\title{
Epithelial defect induced photorefractive surgery: Comparison of two mechanical epithelial removal techniques
}

\author{
Aliagha Alishiri ${ }^{1}$, Mostafa Naderi ${ }^{1}$, Khosro Jadidi ${ }^{1}$, Seyed Aliasghar Mosavi ${ }^{2}$ \\ ${ }^{1}$ Department of Ophthalmology Bina Eye Hospital, Tehran, Iran \\ ${ }^{2}$ Department of Ophthalmology, Bina Eye Hospital Research center, Tehran, Iran
}

Email address:

alishiri20002000@yahoo.com(A. Alishiri),ophthalmology110@yahoo.com(M. Naderi)

\section{To cite this article:}

Aliagha Alishiri, Mostafa Naderi, Khosro Jadidi, Seyed Aliasghar Mosavi. Epithelial Defect Induced Photorefractive Surgery: Comparison of Two Mechanical Epithelial Removal Techniques. Clinical Medicine Research. Vol. 2, No. 4, 2013, pp. 45-47. doi: 10.11648/j.cmr.20130204.11

\begin{abstract}
Purpose: To compare the epithelial defect size after epithelial removal by Weck-Cel sponge (Medtronic) spatula and blunt scalpel hockey blade. Method: This prospective study comprised 100 cases of PRK with mean age of $26 \pm 5$ years (range, 19 to 45) performed at Bina Eye Specialist Hospital from January to march 2012. The size of epithelium removal was the same in all patients and it was $8.5 \mathrm{~mm}^{2}$. Each patienst's right eyes epithelium was removed by Weck spounge and it was removed by Haki spatula in the left eye. The residual epithelial defect size was measured in both eyes after 4 days from surgery. Result: Of 200 eyes that met the inclusion criteria, the mean preoperative spherical equivalent (SE) refractive error in right eyes was $-2.6 \pm 1.5$ (Range: -1 to $-7 \mathrm{D}$ ) versus $2.6 \pm 1.4$ (Range: -1 to $-6.5 \mathrm{D}$ ) in left eyes $(\mathrm{P}=$ $0.527)$. The mean epithelial defect size after 4 days in right eyes was $1.5+-0.77$ and it was $1.46+-0.77$ in the left eyes $(\mathrm{P}=$ 0.623). Conclusion: This sudy showed that there is no difference between corneal epithelial defect size in two methods of PRK surgery after corneal epithelial removal .We consider both methods to be comparable in terms of efficacy and believe the choice of one method over the other rests on the surgeon's decision and experience.
\end{abstract}

Keyword: Photorefractive Surgery, Mechanical Debridement, Epithelial Defect

\section{Introduction}

Photorefractive keratectomy (PRK) is a popular refractive procedure, proven to be effective for correction of refractive errors such as myopia and myopic astigmatism through corneal epithelial removal. [1-2].

Several techniques have been described to remove the epithelium, including mechanical debridement, excimer laser transepithelial ablation, rotating brush and alcoholassisted debridement [3-5]. In all of these procedures, epithelium is lost that causes epitheliual defect, significant postoperative pain, stroma haziness and delay in visual acuity improvement [6].

For several years, Laser in situ keratomileusis (LASIK) was a preferred surface ablation techniques, however, due to certain complications recently trends inclines towards PRK. [7-11].

Mechanical removal is one of the most commonly used techniques that is very effective and straight forward. Epithelial removal using sharp scalpel blades, blunt scalpel blades and Weck-Cel sponge (Medtronic) commonly has been performed for long time. Manual epithelial debridement using sharp scalpel blades reported to leave varying amounts of residual epithelial celles followed by scratches and nick in Bowman's membrane [12]. Furtheremore, a controversy still exists in term of epithelial defect size and epithelial healing duration in different procedures.

To our knowledge, So far there are no reports comparing Weck-Cel sponge (Medtronic) spatula and blunt scalpel hockey blade techniques.

The purpose of this study is to compare epithelial defect size after epithelial removal using simple mechanical removal and to evaluate the safety and efficacy of these techniques.

\section{Methods}

A prospective study was performed on a group of consecutive patients with myopia operated at the Bina Eye 
Hospital from January to march 2012. All patients with good health were included in our study. Subjects with recent refractive surgery or with signs of progressive or unstable myopia, corneal or anterior segment pathology, uncontrolled glaucoma, keratoconus, eyelid disease, untreated retinal abnormalities were excluded. The patients were then divided into two groups. Each patient's right eyes epithelium was removed by Weck-Cel sponge (Medtronic) spatula (group A) and the felow eye; left eye(group B) by blunt scalpel hockey blade. All patients underwent operation by a single surgeon with Technolas laser machine (Technolas 217z100, Bausch \& Lomb, Rochester, NY, USA). The residual epithelial defect size was measured in both eyes after 4 days from surgery because most of previous studies noted approximately 4 days as mean average time to complete healing[13-15]. After primary preparations, and instillation of topical proparacaine $0.5 \%$, the eyes were exposed using a wire lid speculum and epithelium was removed manually in a centripetal fashion using a Weck-Cel sponge spatula on RE and blunt hockey blade on LE.

The diameter of epithelial removal was the same in all patients and it was $8.5 \mathrm{~mm} 2$ that followed by excimer laser ablation. Subsequently, $0.02 \%$ mitomycin $\mathrm{C}$ was applied on the ablated stroma. The duration of mitomycin $\mathrm{C}$ application was 20 seconds. Eyes were irrigated with chilled balanced salt solution and a bandage contact lens (Bausch \& Lomb, Rochester, NY, USA) was placed on the cornea.

The postoperative medication regimen was the same for both eyes and included instilation of ciprofloxacin eye drops immediately after procedure followed by topical $0.5 \%$ chloramphenicol four times a day, betamethasone $0.1 \%$ every 4 hours, diclofenac eye drops every 6 hours, and artificial tears as needed. Bandage contact lenses were removed after 4 days and corneas were stained with fluorescein. The residual epithelial defect $\operatorname{size}(\mathrm{A})$ was calculated using the following equation: $A=\pi[(a+b) / 4] 2$ where $a$ is the shortest dimension of the defect and $b$ is the longest dimension.

Statistical analysis was performed using SPSS 18.0 software (SPSS Inc., Chicago, IL, USA). Chi-square test was also used to compare frequency of data between the two groups. For other comparisons the student t-test or Fisher's exact test was applied. P-values less than 0.05 were considered as statistically significant.

\section{Results}

A total of 100 patients including (44 male and 56 female) with mean age of $26 \pm 5$ years (range, 19 to 45 ) were enrolled in our study. Overall, 100 eyes were allocated to the group A and similarly 100 eyes were assigned to the group B. The Mean preoperative spherical equivalent (SE) refractive error in right eyes was $-2.6 \pm 1.5$ (Range: -1 to -7 D) versus $2.6 \pm 1.4$ (Range: -1 to $-6.5 \mathrm{D})$ in left eyes $(\mathrm{P}=$ 0.527) (Table 1). The mean epithelial defect size after 4 days in right eyes was $1.5 \pm 0.77$ and it was $1.46 \pm 0.77$ in the left eyes $(\mathrm{P}$ value $=0.623)($ Table 2$)$. There was no statistically significant difference in epithelial defect size between the 2 eyes at day 4 postoperative visit.

Table 1. Baseline features in mechanical groups

\begin{tabular}{lcc}
\hline Group A(n=100) & Group B(n=100) & P value \\
\hline $\begin{array}{l}\text { Number of eyes } \\
\text { Preoperative mean } \\
\text { spherical equivalent }\end{array}$ & 100 & 100 \\
$\begin{array}{l}\text { (D) mean (range) } \\
\text { Preoperative mean } \\
\text { spherical equivalent } \\
\text { less than -6 D }\end{array}$ & $-2.6 \pm 1.5(-1$ to -7 D) & $-2.6 \pm 1.4(-1$ to $-6.5 \mathrm{D})$ \\
$\begin{array}{l}\text { Preoperative mean } \\
\text { spherical equivalent } \\
\text { greater than -6 D }\end{array}$ & $99 \%$ & $99.5 \%$ \\
\hline
\end{tabular}

Group A; Patients on Weck-Cel sponge (Medtronic) removal, Group B; Patients on blunt scalpel hockey spatula removal, $\mathrm{p}<0.05$ is based on Pearson chi- square test

Table 2. Postoperative features of study groups

\begin{tabular}{cccc}
\hline & Group A(n=100) & Group B(n=100) & P value \\
\hline $\begin{array}{c}\text { Epithelial defect } \\
\text { (number, }(\%)\end{array}$ & $17(8.5)$ & $17(8.5)$ & - \\
$\begin{array}{c}\text { Epithelial defect } \\
\text { size }\end{array}$ & $1.5 \pm 0.77$ & $1.46 \pm 0.77$ & 0.623 \\
$\begin{array}{c}\text { Duration of } \\
\text { using mitomycin }\end{array}$ & $19.7 \pm 9.7$ & $19.4 \pm 9.3$ & 0.001 \\
\hline
\end{tabular}

Group A; Patients on Weck-Cel sponge (Medtronic) removal, Group B; Patients on blunt scalpel hockey spatula removal, $\mathrm{p}<0.05$ is based on Pearson chi- square test

\section{Discussion}

The healing of epithelial wounds can be divided into several distinct but continuous phases: sliding of superficial cells to cover the denuded surface, cell proliferation, and stratification for re-establishment of multicellular layers. The size and depth of the wound and the nature of the injury affects the healing mode and outcome. [16]. Moreover ,experimental results in our center made controversy in term of remaining epithelial defect size and epithelial healing post Photorefractive keratectomy(PRK) using different mechanical debridement techniques.

In this study we compared epithelial defect size after epithelium removal using simple mechanical debridement by Weck-Cel sponge (Medtronic) spatula and blunt scalpel hockey blade techniques. The diameter of epithelial removal was the same in all patients. The post PK remaining epithelial defect size (A) was calculated similar to other researchers [17] using the equation of $A=\pi$ $[(\mathrm{a}+\mathrm{b}) / 4] 2$.

We found that there is no difference between corneal epithelial defect size in two methods of PRK surgery after corneal epithelial removal $(\mathrm{P}$ value $=0.623)$.

Several studies demonstrated that in the face of exact mechanism of healing, still a controversy exists in term of duration of epithelial healing in different procedures. 
Most of previous studies noted conventional PRK causes slower epithelial healing in comparison to alcohol assisted method. [18]. Study of Abad et al demonstrated a rough stromal bed during mechanical removal that hamper epithelial healing [19]. Also, Ghoreishi et al reported delayed epithelial healing more commonly in the mechanical group at day 7 , however, the difference was of borderline significance $(\mathrm{P}=0.07)$ [17] .

On the contrary, rate of re-epithelialization showed no significant difference in the study of Abad et al in 1996. [20].

Our study showed no significant difference between corneal epithelial defect size post PRK that is in accordance to study of Abad et al. [21].

Also, Luo Lu et al [16] demonstrated that size and depth of the wound and the nature of the injury play a role on healing mode and outcome. The diameter of epithelial removal was the same in all patients and it was $8.5 \mathrm{~mm} 2$. So, It might be concluded that simple mechanical epithelial debridement using Weck-Cel sponge (Medtronic) spatula or blunt scalpel hockey blade may make relatively similar nature and depth of injury during PRK.

In summary, we observed no significant difference between 2 simple mechanical epithelial debridement methods for PRK. We consider both methods to be comparable in terms of efficacy and believe the choice of one method over the other rests on the surgeon's decision and experience.

\section{References}

[1] Biswell R. Cornea. In: Riordan-Eva P, Whitcher JP(eds). Vaughan \& Asbury's General Ophthalmology. 16th ed. New York: Lange; 2004: 152

[2] Rajan MS, Jaycock P, O'Brart D, et al. A long-term study of photorefractive keratectomy; 12-year follow-up. Ophthalmology 2004; 111(10): 1813-24.

[3] Weiss, RA, Lih-Huei, L, Liaw, MS, Berns, M, Amoils, SP. (1999) Scanning electron microscopy comparison of corneal epithelial removal techniques before photorefractive keratectomy J Cataract Refract Surg 25, 1093-1096

[4] Griffith, M, Jackson, B, Lafontaine, MD, et al (1998) Evaluation of current techniques of corneal epithelial removal in hyperopic photorefractive keratectomy J Cataract Refract Surg 24, 1070-1078

[5] Pallikaris IG, Karoutis AD, Lydataki SE, Siganos DS. Rotating brush for fast removal of corneal epithelium. J Refract Corneal Surg 1994; 10439-442.

[6] Gimbel HV, DeBroff BM, Beldavs RA, van Westenbrugge JA, Ferensowicz M. Comparison of laser and manual removal of corneal epithelium for photorefractive keratectomy. J Refract Surg 1995; 11: 36-41.

[7] Hersh PS, Brint SF, Maloney RK, Durrie DS, Gordon M, Michelson MA, et al. Photorefractive keratectomy versus laser in situ keratomileusis for moderate to high myopia. A randomized prospective study. Ophthalmology 1998; 105: $1512-1522$

[8] Pop M, Payette Y. Photorefractive keratectomy versus laser in situ keratomileusis: a controlmatched study. Ophthalmology 2000; 107: 251-257.

[9] Kasetsuwan N, Puangsricharern V, Pariyakanok L. Excimer laser photorefractive keratectomy and laser in situ keratomileusis for myopia and astigmatism. J Med Assoc Thai 2000; 83: 182-192.

[10] 10. Ghadhfan F, Al-Rajhi A, Wagoner MD. Laser in situ keratomileusis versus surface ablation: visual outcomes and complications. J Cataract Refract Surg 2007; 33:2041-2048

[11] Ghadhfan F, Al-Rajhi A, Wagoner MD. Laser in situ keratomileusis versus surface ablation: visual outcomes and complications. J Cataract Refract Surg 2007; 33: 2041-2048

[12] Campos M, Hertzog L, Wang XW, Fasano AP, McDonnell PJ. Corneal surface after deepithelialization using a sharp and a dull instrument. Ophthalmic Surg 1992; 23: 618-621.

[13] Lee JB, Seong GJ, Lee JH, et al. Comparison of laser epithelial keratomileusis and photorefractive keratectomy for low o mod-erate myopia. J Cataract Refract Surg 2001; 27:565-570

[14] Buzzonetti L, Petrocelli G, Laborante A, Mazzilli E, Gaspari M, Valenti P, Francia E. A new transepithelial phototherapeutic keratectomy mode using the NIDEK CXIII excimer laser. J Refract Surg 2009; 25: S122-S124

[15] Ali Fadlallah A, Fahed D, Khalil K et al. Transepithelial photorefractive keratectomy:Clinical results: J Cataract Refract Surg Volume 37, Issue 10, Pages 1852-1857, October 2011.

[16] Luo Lu, Peter S. Reinach and Winston W.-Y. Kao. Corneal Epithelial Wound Healing Experimental Biology and Medicine 2001, 226: 653-664.

[17] Engle AT, Laurent JM, Schallhorn SC, Toman SD, Newacheck JS, Tanzer DJ, Tidwell JL. Masked comparison of silicone hydrogel lotrafilcon A and etafilcon A extendedwear bandage contact lenses after photorefractive keratectomy. J Cataract Refract Surg 2005; 31: 681-686

[18] Abad JC, An B, Power WJ, Foster CS, Azar DT, Talamo JH. A prospective evaluation of alcohol-assisted versus mechanical epithelial removal before photorefractive keratectomy. Ophthalmology. 1997; 104: 1566-1574.

[19] Lee HK, Lee KS, Kim JK, Kim HC, Seo KR, Kim EK. Epithelial healing and clinical outcomes in excimer laser photorefractive surgery following three epithelial removal techniques: mechanical, alcohol, and excimer laser. Am J Ophthalmol. 2005; 139: 56-63.

[20] Ghoreishi1 et al. Alcohol-assisted versus Mechanical Epithelium Removal in Photorefractive Keratectomy. J Ophthalmic Vis Res 2010; 5 (4): 223-227.

[21] Abad JC, Talamo JH, Vidaurri-Leal J, Cantu-Charles C, Helena MC. Dilute ethanol versus mechanical debridement before photorefractive keratectomy.J Cataract RefractSurg.1996; 22: 1427-1433. 